\title{
No Longer Silenced: What Learning Resources Do Child Abuse Survivors Want?
}

\author{
Nicolette Winn \\ No Longer Silenced Movement, Dallas, USA
}

\author{
Cheryl K. Stenmark \\ Angelo State University, San Angelo, USA
}

\begin{abstract}
Much attention has been paid to the adverse effects of maltreatment during childhood. Many researchers have examined the effects of child abuse, but much less attention has been paid to determining what resources may be useful in aiding child abuse survivors in achieving successful lives as adults. Thus, the present study extends previous research by exploring what learning resources are reported as being most desired by child abuse survivors and non-abused individuals. Child abuse survivors reported the greatest desire in utilizing learning resources related to interpersonal skills, finding a job, and keeping a job. Non-abused individuals reported the greatest desire in utilizing learning resources related to finding a job, work ethic, and interpersonal skills. Data from this study will be used in the creation and implementation of programs aimed at helping child abuse survivors succeed in independent adult living via the philanthropic movement, No Longer Silenced Movement (NLSM).

Keywords: child abuse, child abuse resources, child abuse recovery, child abuse effects, detrimental effects of child abuse learning resources, child abuse survivors, adult survivors of child abuse, no longer silenced movement
\end{abstract}

\section{Introduction}

Child abuse is a significant problem all over the world. In an average year, an estimated 3.3 million children are referred to child protective services (Schradley, Turner, \& Gotlib, 2002). In addition to the staggering numbers of cases of abuse, child abuse results in enormous financial costs. In a single year, the United States government spent a combined \$25 billion dollars to run the country's child welfare program at the federal, state, and local levels (Ross, 2010). Per victim of nonfatal child maltreatment, the estimated average lifetime cost is $\$ 210,012$ in 2010 , including $\$ 32,648$ in childhood health care costs, $\$ 10,530$ in adult medical costs, $\$ 144,360$ in productivity losses, $\$ 7,728$ in child welfare costs, $\$ 6,747$ in criminal justice costs, and \$7,999 in special education costs (Fang, Brown, Florence, \& Mercy, 2012). According to Wang and Holton (2007), the overall estimated cost of child abuse exceeds $\$ 100$ billion per year. Considering these statistics, it is apparent that the United States is spending billions of dollars each year in its effort to aid millions of children; however, the fate of these children after they age out of childhood also needs to be considered.

There are a number of negative effects of childhood maltreatment that extend into adulthood, including higher rates of unemployment, teenage pregnancy, homelessness, alcohol and drug use, and mental health problems, as compared with individuals who were not maltreated as children (Jackson \& Martin, 1998; Thornberry, Ireland, \& Smith, 2001). These outcomes occur regardless of gender and childhood socioeconomic 
status (SES). Indeed, while controlling for gender and childhood SES, Herrenkohl, Seunghye, Klika, Herrenkohl, and Russo (2013) found that adult survivors of childhood maltreatment were more likely to be depressed, anxious, and suffer more mental and physical health problems. Thus, it is apparent that the effects of childhood maltreatment can span a wide range of impairments in adulthood. By examining these different areas of impairment individually, researchers can develop interventions to help adult survivors of childhood abuse cope with the long-term damaging effects of the abuse they experienced. Thus, the present study seeks to determine the areas about which the survivors of childhood abuse are most interested in learning to help aid their pursuit of a successful life. Before turning to the resources most desired by child abuse survivors, an initial examination of the different areas of research on child abuse is instructive in order to help foster understanding of the effects of child abuse. Within the context of these deleterious effects, what challenges child abuse survivors may face becomes more apparent, which could hinder their efforts to achieve their personally desired success in adult life.

\section{Mental Health, Stress, and Physical Health}

\section{Mental Health}

A number of mental health issues are related to childhood abuse, including an increase in the likelihood of experiencing attention deficit disorders, and adults who were maltreated as children experience increased suicide attempts (Dube, Anda, Felitti, Chapman, Williamson, \& Giles, 2001). In a longitudinal study examining the relationship between childhood and adolescent physical and sexual abuse before the age of 18 and psychosocial functioning in mid-adolescence (age 15) and early adulthood (age 21), Silverman, Reinherz, and Giaconia (1996) found that approximately $80 \%$ of the abused young adults met DSM-III-R criteria for at least one psychiatric disorder in early adulthood. Specifically, compared with non-abused individuals, abuse survivors exhibited considerable impairments in functioning both at ages 15 and at 21 , including more depression, anxiety, psychiatric disorders, suicidal ideation, suicide attempts, and emotional-behavioral problems. Child abuse interferes with a child's ability to acquire appropriate emotional regulation skills, and this can lead to greater emotional dysregulation, with the possibility of this dysregulation continuing into adulthood (Artime \& Peterson, 2010; Burns, Jackson, \& Harding, 2010; Ciccheti \& White, 1990; Collin-Vézina, Isabelle, \& Martine, 2013; Schelble, Franks, \& Miller, 2010). Indeed, Thompson, Arias, Basile, and Desai (2012) found that, in comparison to their non-maltreated peers, women who were abused as children experience greater emotional disabilities.

\section{Stress}

Research demonstrates links between stress and child abuse. These links may have the potential to interfere with child abuse survivors' progress in achieving success in adult life, as it may be difficult for survivors to focus on striving to achieve goals at the same time that they are battling stress and its negative effects. For example, housing insecurity associated with maternal stress is directly related to abuse and neglect risk (Warren \& Font, 2015). These negative results, however, can be reduced via interventions. Kimbrough, Magyari, Langenberg, Chesney, and Berman (2010) found that an 8-week mindfulness mediation-based stress reduction (MBSR) program and daily home practice of mindfulness skills reduced depressive symptoms by $65 \%$. The abuser's stress is often a cause of child abuse, and the child abuse is often, not surprisingly, a cause of a great deal of stress for the child. This stress can have serious long-term negative effects for the child. 
Stress induced by childhood trauma, including child abuse, can cause serious life-changing effects on a child. During critical periods of brain development, disruption can lead to major abnormalities or neurodevelopmental deficits, which can in turn negatively affect a child across several areas of functioning including cognitive, behavioral, social, and affective functioning (Perry, Pollard, Blakely, Baker, \& Vigilante, 1995; Soloman \& Heide, 2005; Terr, 1983, 1991). Extreme stress also causes the body to respond by releasing hormones such as cortisol and adrenaline, which have been linked to brain cell damage, homeostasis disruption, memory impairment, and issues with both the sympathetic nervous and endocrine systems. Changes in these systems are linked to changes in other systems including the cardiovascular, respiratory, and muscular systems (Soloman \& Heide, 2005). The majority of the existing brain studies have been conducted on adults; however, the few studies on children and adolescents who have been maltreated support that maltreated children experience altered brain structure and functioning (Jackowski, De Araújo, De Lacerda, De Jesus Mari, \& Kaufman, 2009). Following exposure to a serious traumatic event or events, children remain in a state of hyperarousal or dissociation (Perry et al., 1995). Hyperarousal occurs when children who are exposed to chronic, traumatic stress develop pathways in the brain for fear response and create memories that automatically trigger that response without conscious thought. Children who are hyperaroused have an altered baseline for arousal and will overact to trigger other children find nonthreatening (Child Welfare Information Gateway, 2015).

PTSD is a form of hyperarousal response and is a mental health disorder in which child maltreatment is a predominant form of the trauma experienced by the affected individual (Collin-Vézina et al., 2013; Ginsberg, Nakelrud, \& Larrison, 2004; Kandel, Schwartz, \& Jessell, 2000; Solomon \& Heide, 2005). According to APA (2009), "Symptoms of PTSD can include flashbacks or dreams of the event, diminished interest or participation in significant activities, feelings of detachment or estrangement from others, restricted range of affect, difficulty falling or staying asleep, irritability or outbursts of anger, difficulty concentrating, hypervigilance, and exaggerated startle response".

Adults who have PTSD are also likely to experience more autonomic hyperactivity as well as anxiety, agitation, and panic (Krystal, Kosten, Southwick, Mason, Perry, \& Giller, 1989). Overall, evidence suggests that childhood trauma interferes with central nervous system maturation and causes lasting neurological changes due to the amount of stress induced by the mistreatment (Van der Kolk, 1987).

\section{Physical Health}

Maltreatment in early childhood has also been linked to adverse physical health outcomes in adulthood (Walker et al., 1999). It may be difficult for survivors to strive to achieve their goals when they are consumed with battling ill health. For instance, in comparison to their non-abused siblings, abused children had poorer nutritional status (Nakou, Adam, Stathacopoulou, \& Agathonos, 1982). Additionally, child abuse is associated with an increased number of sexual partners and STI diagnoses as well as an increased likelihood to trade sex for drugs or money (Artime \& Peterson, 2010; Senn, Carey, Vanable, Coury-Doniger, \& Urban, 2006). In comparison to their non-maltreated peers, women who were abused as children have greater physical disabilities, as well as nearly doubled average self-reported health care costs (Tang, Jamieson, Boyle, Libby, Gafni, \& MacMillan, 2006; Thompson et al., 2002). Walker et al. (1999) suggests that, although the costs per year per woman may not seem like much, when taking into account the considerable number of women in the population who have these experiences, it is apparent that the total costs to society are substantial. 


\section{Interpersonal Skills, Shame, and Incarceration}

\section{Interpersonal Skills}

According to Shields and Cicchetti (1998), child abuse hinders children from developing appropriate interpersonal skills, and they may not be willing to take the risk of forming an attachment with a romantic partner as adults because they view people as not safe, predictable, or trustworthy (Alexandrov, Cowan, \& Cowan, 2005). For example, maltreatment in childhood has been linked to difficulties in adult romantic areas including intimacy, sexual adjustment, and conflict resolution as well as being more likely to select a partner who mistreats them (Alpher \& France, 1993; DiLillo, Lewis, \& Di Loreto-Colgan, 2007). Child abuse survivors may be more likely to select a partner who mistreats them because they may not perceive their partner's behavior as mistreatment. Indeed, Miller-Perrin, Wurtele, and Kondrick, (1990) found significant differences between abused and non-abused children's conceptions of personal body safety with regard to their definitions of sexual abuse.

\section{Shame}

Shame in child abuse survivors has been shown to contribute to increased interpersonal conflict, as it can lead to an increase in psychological distress and emotional problems that can hinder intimate relationships (Feiring, 2005; Kim, Talbot, \& Cicchetti, 2009). Child abuse survivors who feel shame related to their abuse may not let others get too close because they may feel unworthy of love (Loader, 1998). Additionally, in comparison to their peers who were not abused, abused children are more likely to be aggressive (Shields \& Chiccetti, 1998). This is evident in one study in which one-third of young men and $18 \%$ of young women were reported partaking in illegal activity during the past month with commonly reported behaviors included intentional damage to property as well as voluntary participation in group fights (Courtney et al., 2011). It has also been reported that foster youth have more discipline problems in school (Blome, 1997).

Shame may lead survivors to refrain from seeking help because they may be embarrassed about what happened to them. They may believe that if they reached out for help, people may ask them to reveal specifics about their abuse, which may cause them to feel shame. Because they do not want to feel this shame, they may be less likely to seek help. The present study provides child abuse survivors with an opportunity to reveal what learning resources they desire while removing some of the potential shame of having to reveal what happened to them, in order to seek help. The implementation of programs designed to help child abuse survivors succeed in independent adult living could potentially reduce survivor shame in several ways. For example, such programs could provide role models who have also experienced abuse, and yet have succeeded in their desired achievements despite their past abuse. This can help survivors understand that they can still succeed in achieving their goals despite any shame, which they may feel, which might make them feel like they do not deserve success.

\section{Incarceration}

Finally, in adult survivors of child abuse, nearly one-third of the young women and two-thirds of the young men reported that they had spent at least one night in jail since they were 17 or 18 years old (Courtney et al., 2011). Multiple studies have shown a link between child abuse and incarceration, including one reporting that $44 \%$ of incarcerated women had suffered physical or sexual abuse, another reporting that $90 \%$ experienced interpersonal trauma with $50 \%$ being molested as children, and another reporting $70 \%$ of interviewed participants reporting being survivors of sexual abuse (Banyard \& Williams, 2007; Greenfield \& Snell, 1999; Lynch, Fritch, \& Heath, 2012). 


\section{Employment and Academics}

\section{Employment}

According to Courtney et al. (2011), participants who were survivors of child abuse reported working an average of 36 hours per week with a median of 40 hours per week. Despite these working hours, two-thirds of young women and $42 \%$ of young men who experienced abuse during childhood reported that they had been recipients of food stamps. Participants who were employed part-time (less than 35 hours per week) reported that they wanted full-time work and cited being unable to find full-time work and slack work or business conditions as the most common reasons for working part-time. It is also possible that the detrimental effects of child abuse in areas including mental, physical, emotional, and social health make it difficult for child abuse survivors to find and maintain full-time work. Survivors may likely be unable to attend work regularly due to disabilities such as PTSD and increased illness. Furthermore, survivors may have a difficult time getting hired or maintaining working relationships because they lack the necessary social skills.

\section{Academics}

According to the US Department of Health and Human Services (2001), 92\% of the US children in foster care had been removed from their homes due to neglect, physical abuse, and sexual abuse, and $41 \%$ of the foster care children had experienced multiple forms of maltreatment in their homes of origin. Thus, the research on foster youth can help to influence the development interventions aimed at helping child abuse survivors. Foster care children are more likely to lag behind peers academically and less likely to have adults in their lives who monitor homework (Blome, 1997; Dworsky, Smithgall, \& Courtney, 2014; Schelble et al., 2010). In comparison to children from intact families, foster youth were significantly less likely to be on a college preparatory track, finish high school, or earn a GED (Blome, 1997; Dworsky et al., 2014). Following high school, foster youth are less likely to earn a college degree, let alone enroll in college, despite their aspirations to do so (Courtney et al., 2011; Dworsky et al., 2014). According to Courtney et al. (2011), only 8\% of the young adults examined in the study, who were previous foster youth, had a degree from a 2-or-4-year school, and regardless of gender, being unable to pay for school was cited, by far, as the most common barrier.

Thus, it is clear that children who have experienced abuse exhibit a number of detrimental outcomes due to that abuse, and they are likely to continue experiencing detrimental outcomes related to that abuse in adulthood. Courtney et al. (2011) reported that only slightly less than half to roughly two-thirds of child abuse survivors were reported that they had enough people to whom they could turn for resources and to help them with their problems. Thus, the present study seeks to determine topics about which child abuse survivors might be interested in obtaining learning resources so that programs can be developed and implemented to help them succeed in independent adult living. These programs would provide child abuse survivors with support, which, according to research (e.g., Courtney et al., 2011), are likely to be lacking, via the philanthropic movement, No Longer Silenced Movement (NLSM).

\section{Method}

\section{Participants}

Participants were 159 students attending a medium-sized southwestern university, with 33 males, 124 females, and 2 who preferred not to answer. The mean age of participants was 20.54 years $(S D=4.02)$. There were 26 respondents who were identified as survivors of childhood abuse, representing approximately $16 \%$ of 
total participants. According to the U.S. Department of Health and Human Services (2013), 47.1 out of every 1,000 , or roughly $5 \%$ of children were reported abused in a single year. So, although $16 \%$ may seem low, it is most likely an accurate representation of child abuse survivors, if not an over-representation, in comparison with the previous report. Participants volunteered to participate in this research to fulfill a course requirement or receive extra credit for a class. The purpose of the study was described as to determine about what learning resources independence young adults would be interested in utilizing.

\section{Measures}

Independent living resources. In order to help determine what resources are desired by child abuse survivors to be successful in independent adult living, the researchers developed a 67-item questionnaire asking about a variety of topics about what young adults may be interested in learning. The instructions of the questionnaire read: "Below is a list of life skills that may be considered necessary for success in adult independence. These are topics that some people may be interested in utilizing resources for learning more about them. Each topic indicates the extent to which you agree that having learning resources available to you would be something you would be interested in. Please be open and honest in your responding".

The 67-items (e.g., Building Credit/Credit Score, Register to Vote, Job Application) were rated on a 7-point Likert-type scale.

Demographic data. A questionnaire requesting information about various facets of each participant's demographic background was administered. Due to the sensitive nature of the study, minimal demographic data were collected. Participants were self-identified as survivors of child abuse by responding "Yes" or "No" to a question asking if they were identified as a survivor of child abuse. Recollection of instances of abuse may trigger mental health issues, and because there was not a licensed mental health professional on hand for this study, minimal information pertaining to the type of abuse, age of onset, etc. was collected to protect the safety and well-being of participants.

\section{Procedure}

The anonymous survey was completed via Survey Monkey at a time and location of participants' choosing. Participants were initially presented with an informed consent form briefly explaining the purpose of the study. Following the informed consent form, participants completed the Independent Living Resources survey. Finally, participants were asked to complete a brief demographic survey. After completing the survey, participants were presented with a debriefing form that explained the purpose of the study and provided them with researcher contact information as well as with a number to contact in case of trigger.

\section{Results}

The present study used a descriptive analysis in order to compare the responses of child abuse survivors and non-abused individuals and to determine the relative importance of the different learning resources to these different groups. It is important to understand the differences in desired learning resources in order to develop programs to help child abuse survivors. For example, without this knowledge, one may argue that the results of the study are applicable to both survivors and non-abused individuals. Furthermore, it is also important to understand the priority of survivor needs in order to prioritize program development.

In order to determine what types of resources survivors of childhood abuse are most interested in, we first conducted an analysis of the descriptive statistics for the separate questionnaire items. This analysis showed 
that differences exist between child abuse survivors and non-abused individuals as to what learning resources they desired most. There were a number of differences, but the differences in the top five most desired resources are particularly interesting (See Tables 1 and 2). Child abuse survivors reported the greatest desire in utilizing learning resources related to Interpersonal Skills $(M=5.68, S D=0.84)$ followed by Finding a Job ( $M$ $=5.68, S D=0.88)$ and Keeping a Job $(M=5.65, S D=0.89)$. Child abuse survivors were also interested in utilizing learning resources about Communication Skills $(M=5.68, S D=0.75)$ and Job Applications $(M=5.62$, $S D=0.90)$. Non-abused individuals reported the greatest desire in utilizing learning resources related to Finding a Job $(M=5.68, S D=0.84)$ followed by Work Ethic $(M=5.68, S D=0.84)$ and Interpersonal Skills $(M$ $=5.68, S D=0.84)$. Non-abused individuals were also interested in utilizing learning resources about Avoiding Debt $(M=5.68, S D=0.84)$ and Thinking Skills $(M=5.68, S D=0.84)$.

Table 1

Descriptive Statistics of Questionnaire Items for Childhood Abuse Survivors

\begin{tabular}{|c|c|c|}
\hline Questionnaire item & Mean & $S D$ \\
\hline Interpersonal Skills & 5.69 & 0.84 \\
\hline Finding a Job & 5.69 & 0.88 \\
\hline Keeping a Job & 5.65 & 0.89 \\
\hline Communication Skills & 5.65 & 0.75 \\
\hline Job Application & 5.62 & 0.90 \\
\hline Comply with Laws, Regulations & 5.62 & 0.70 \\
\hline Thinking Skills & 5.56 & 1.04 \\
\hline Stress Management; A Basic Guide to Stress Management & 5.50 & 1.24 \\
\hline Renting; A Basic Guide to Renting Your Home & 5.48 & 0.92 \\
\hline Self-Defense & 5.46 & 1.27 \\
\hline Vehicle Ownership; Title and Registration & 5.42 & 1.27 \\
\hline Ownership; A Basic Guide to Buying Your Home & 5.42 & 1.14 \\
\hline Relationships; Developing and Maintaining Healthy Relationships & 5.38 & 1.30 \\
\hline Work Ethic & 5.38 & 1.20 \\
\hline Etiquette & 5.38 & 1.20 \\
\hline Maintain Safe Identity & 5.35 & 1.23 \\
\hline Utilities; How to Set Up And Pay Utilities (Ex: Electricity, Water) & 5.35 & 1.16 \\
\hline Vehicle Ownership; Purchasing Insurance & 5.35 & 1.29 \\
\hline Vehicle Maintenance; A Basic Guide to Simple Vehicle Maintenance & 5.31 & 1.41 \\
\hline Personal Development; Learn about Talents, Interests, Skills, Personality & 5.31 & 1.26 \\
\hline Mental Health & 5.31 & 1.54 \\
\hline Resume & 5.31 & 1.29 \\
\hline Vehicle Ownership; Buying a Vehicle & 5.31 & 1.29 \\
\hline Validate Sources of Information & 5.31 & 1.26 \\
\hline Budgeting & 5.28 & 1.51 \\
\hline Be Environmentally Responsible & 5.27 & 1.12 \\
\hline Driver's Responsibility; Following Laws & 5.27 & 1.31 \\
\hline $\begin{array}{l}\text { Explore Tertiary Options (Tertiary refers to education that occurs following high } \\
\text { school (Grades 9-12). This includes undergraduate, postgraduate, technical training } \\
\text { institutes, and centers for excellence (real estate, personal training, etc.) }\end{array}$ & 5.27 & 1.19 \\
\hline Taxes & 5.24 & 1.45 \\
\hline Driver's License; Getting Your Driver's License & 5.23 & 1.31 \\
\hline Physical Fitness; A Basic Weekly Exercise Routine & 5.23 & 1.31 \\
\hline Physical Health; A Basic Guide to Routine Medical Care & 5.19 & 1.33 \\
\hline
\end{tabular}


Table 1 to be continued

\begin{tabular}{|c|c|c|}
\hline Birth Certificate; Getting Your Birth Certificate & 5.19 & 1.47 \\
\hline Personal Safety & 5.19 & 1.44 \\
\hline Personal Development; Explore Hobbies/Social/Recreational Opportunities & 5.15 & 1.32 \\
\hline Dental Health & 5.15 & 1.41 \\
\hline Medication; Safe Usage & 5.12 & 1.51 \\
\hline Open, Use, and Balance A Checking Account & 5.12 & 1.61 \\
\hline Getting Your State ID & 5.12 & 1.31 \\
\hline Vote & 5.12 & 1.37 \\
\hline Avoiding Debt & 5.08 & 1.72 \\
\hline Register to Vote & 5.08 & 1.29 \\
\hline Keeping Track of Documents & 5.04 & 1.70 \\
\hline Social Security Card; Getting Your Social Security Card & 5.04 & 1.46 \\
\hline Nutrition; A Basic Weekly Plan For a Healthy Diet & 5.04 & 1.64 \\
\hline Driver's Responsibility; Navigation, Reading a Map and Using GPS & 5.04 & 1.28 \\
\hline Maintenance; A Basic Guide to Simple Home Maintenance & 5.04 & 1.28 \\
\hline Location Housing Options & 5.04 & 1.31 \\
\hline Upkeep; A Basic Guide to Upkeep of Your Home (Ex: Cleaning, Laundry) & 5.00 & 1.26 \\
\hline Nutrition; Basic Food Preparation & 5.00 & 1.65 \\
\hline Medication; Safe Storage & 5.00 & 1.52 \\
\hline Public Transportation; A Basic Guide to Using Public Transportation & 5.00 & 1.23 \\
\hline State Identification & 4.96 & 1.43 \\
\hline How to Use a Bank, an ATM, and Online Banking & 4.96 & 1.43 \\
\hline Cover Letter & 4.96 & 1.18 \\
\hline Nutrition; Understanding Nutrition Labels & 4.96 & 1.40 \\
\hline Building Credit/Credit Score & 4.96 & 1.66 \\
\hline Cyber Presence/Safety & 4.96 & 1.27 \\
\hline Open and Use a Savings Account & 4.92 & 1.62 \\
\hline Vehicle Ownership; Leasing a Vehicle & 4.85 & 1.59 \\
\hline Nutrition; Where to Get Food (Store, Food Banks, Grow Your Own) & 4.81 & 1.63 \\
\hline Volunteer & 4.73 & 1.19 \\
\hline Nutrition; How To Use Kitchen Appliances & 4.62 & 1.60 \\
\hline Investing & 4.58 & 1.63 \\
\hline In Most Ways My Life Is Close to My Ideal. & 4.50 & 1.68 \\
\hline Participate in Community Activities & 4.46 & 1.53 \\
\hline Dress in Business Attire & 4.23 & 1.66 \\
\hline Bicycling & 3.92 & 1.47 \\
\hline
\end{tabular}

Table 2

Descriptive Statistics of Questionnaire Items for Non-childhood Abuse Survivors

\begin{tabular}{lll}
\hline Questionnaire item & Mean & $S D$ \\
\hline Finding a Job & 5.81 & 0.75 \\
Work Ethic & 5.75 & 0.88 \\
Interpersonal Skills & 5.75 & 0.74 \\
Avoiding Debt & 5.70 & 0.93 \\
Thinking Skills & 5.69 & 0.93 \\
Budgeting & 5.69 & 0.88 \\
Communication Skills & 5.68 & 0.89 \\
Self-Defense & 5.67 & 0.73 \\
\hline
\end{tabular}


Table 2 to be continued

\begin{tabular}{|c|c|c|}
\hline Keeping a Job & 5.67 & 0.97 \\
\hline Job Application & 5.66 & 0.74 \\
\hline Open, Use, and Balance A Checking Account & 5.59 & 0.95 \\
\hline Stress Management; A Basic Guide to Stress Management & 5.59 & 0.92 \\
\hline Nutrition; A Basic Weekly Plan for a Healthy Diet & 5.59 & 0.76 \\
\hline Relationships; Developing and Maintaining Healthy Relationships & 5.58 & 0.96 \\
\hline Open and Use a Savings Account & 5.57 & 0.98 \\
\hline Comply with Laws, Regulations & 5.56 & 0.96 \\
\hline Maintain Safe Identity & 5.54 & 1.00 \\
\hline Vehicle Ownership; Purchasing Insurance & 5.54 & 0.97 \\
\hline Personal Development; Explore Hobbies/Social/Recreational Opportunities & 5.53 & 0.93 \\
\hline Building Credit/Credit Score & 5.53 & 1.09 \\
\hline Resume & 5.53 & 0.88 \\
\hline Personal Safety & 5.52 & 1.09 \\
\hline Personal Development; Learn About Talents, Interests, Skills, Personality & 5.52 & 0.92 \\
\hline Physical Fitness; A Basic Weekly Exercise Routine & 5.49 & 0.87 \\
\hline Vehicle Ownership; Title And Registration & 5.49 & 1.01 \\
\hline Mental Health & 5.49 & 1.12 \\
\hline Physical Health; A Basic Guide to Routine Medical Care & 5.49 & 0.94 \\
\hline Taxes & 5.48 & 1.02 \\
\hline Vehicle Ownership; Buying a Vehicle & 5.47 & 1.01 \\
\hline Etiquette & 5.46 & 0.97 \\
\hline Nutrition; Basic Food Preparation & 5.45 & 0.92 \\
\hline Keeping Track of Documents & 5.44 & 1.11 \\
\hline Vote & 5.44 & 1.11 \\
\hline Ownership; A Basic Guide to Buying Your Home & 5.44 & 0.99 \\
\hline Utilities; How to Set Up and Pay Utilities (Ex: Electricity, Water) & 5.42 & 1.12 \\
\hline How to Use a Bank, an ATM, and Online Banking & 5.40 & 1.16 \\
\hline Dental Health & 5.38 & 1.11 \\
\hline Medication; Safe Usage & 5.36 & 1.20 \\
\hline Vehicle Maintenance; A Basic Guide to Simple Vehicle Maintenance & 5.35 & 1.07 \\
\hline Validate Sources of Information & 5.35 & 1.12 \\
\hline Social Security Card; Getting Your Social Security Card & 5.35 & 1.27 \\
\hline Nutrition; Where to Get Food (Store, Food Banks, Grow Your Own) & 5.34 & 1.15 \\
\hline $\begin{array}{l}\text { Explore Tertiary Options (Tertiary refers to education that occurs following high } \\
\text { school (Grades 9-12). This includes undergraduate, postgraduate, technical training } \\
\text { institutes, and centers for excellence (real estate, personal training, etc.) }\end{array}$ & 5.34 & 1.23 \\
\hline Register to Vote & 5.34 & 1.19 \\
\hline Maintenance; A Basic Guide to Simple Home Maintenance & 5.34 & 0.87 \\
\hline Investing & 5.34 & 1.13 \\
\hline Be Environmentally Responsible & 5.34 & 1.05 \\
\hline Renting; A Basic Guide to Renting Your Home & 5.33 & 0.99 \\
\hline Medication; Safe Storage & 5.32 & 1.22 \\
\hline State Identification & 5.29 & 1.24 \\
\hline Cyber Presence/Safety & 5.28 & 1.17 \\
\hline Driver's License; Getting Your Driver's License & 5.27 & 1.36 \\
\hline Nutrition; Understanding Nutrition Labels & 5.26 & 1.14 \\
\hline Driver's Responsibility; Following Laws & 5.26 & 1.28 \\
\hline Getting Your State ID & 5.25 & 1.25 \\
\hline
\end{tabular}


Table 2 to be continued

\begin{tabular}{lll}
\hline Location Housing Options & 5.19 & 1.09 \\
Volunteer & 5.19 & 1.05 \\
Birth Certificate; Getting Your Birth Certificate & 5.19 & 1.30 \\
Driver's Responsibility; Navigation, Reading a Map and Using GPS & 5.18 & 1.27 \\
Nutrition; How to Use Kitchen Appliances & 5.16 & 1.29 \\
Upkeep; A Basic Guide to Upkeep of Your Home (Ex: Cleaning, Laundry) & 5.15 & 1.29 \\
Vehicle Ownership; Leasing a Vehicle & 5.13 & 1.21 \\
Participate in Community Activities & 5.12 & 1.13 \\
Cover Letter & 5.05 & 1.11 \\
In Most Ways My Life Is Close to My Ideal. & 4.95 & 1.17 \\
Dress in Business Attire & 4.93 & 1.16 \\
Public Transportation; A Basic Guide to Using Public Transportation & 4.82 & 1.36 \\
Bicycling & 4.29 & 1.49 \\
\hline
\end{tabular}

In addition to the analysis of the individual items, we also categorized the items into dimensions and examined which general dimensions of learning resources were most desirable to child abuse survivors and non-abused individuals. We used a rational approach to categorize the individual items on the questionnaire into dimensions; four Industrial-organizational psychologists independently grouped the items according to similarity of concepts. Then, the four judges compared groupings, discussed discrepancies, and agreed upon a final set of 11 dimensions (see Table 3). This analysis revealed that child abuse survivors are most interested in resources associated with Interpersonal Improvement $(M=5.53, S D=0.17)$, followed by Personal Improvement $(M=5.32, S D=0.17)$, Employment $(M=5.26, S D=0.52)$, Safety/Security $(M=5.25, S D=$ $0.19)$, and their Residence $(M=5.22, S D=0.22)$. Non-abused individuals of childhood abuse, however, were most interested in resources associated with Interpersonal Improvement $(M=5.62, S D=0.13)$, followed by Finance $(M=5.54, S D=0.13)$, Personal Improvement $(M=5.52, S D=0.14)$, Employment $(M=5.49, S D=$ $0.35)$, and Safety/Security $(M=5.47, S D=0.16)$. See Table 4 for the rankings of the other categories for survivors of child abuse and non-abused individuals.

Table 3

Independent Living Questionnaire Dimensions

\begin{tabular}{ll}
\hline 1. Civic Duty & 7. Health \\
\hline Register to Vote & Dental Health \\
Vote & Medication: Safe Storage \\
Comply with Laws, Regulations & Medication: Safe Usage \\
Be Environmentally Responsible & Physical Health: A Basic Guide to Routine Medical Care \\
Participate in Community Activities & Physical Fitness: A Basic Weekly Exercise Routine \\
Volunteer & Mental Health \\
\hline 2. Employment & Stress Management: A Basic Guide to Stress Management \\
\hline Dress in Business Attire & 8. Nutrition \\
Cover Letter & Nutrition: A Basic Weekly Plan for a Healthy Diet \\
Resume & Nutrition: Basic Food Preparation \\
Finding a Job & Nutrition: How to Use Kitchen Appliances \\
Job Application & Nutrition: Understanding Nutrition Labels \\
Keeping a Job & Nutrition: \\
Work Ethic & Where to Get Food (Store, Food Banks, Grow Your Own) \\
\hline
\end{tabular}


Table 3 to be continued

\begin{tabular}{|c|c|}
\hline 3. Interpersonal Improvement & 9. Safety/Security \\
\hline Etiquette & Personal Safety \\
\hline Communication Skills & Self-Defense \\
\hline Interpersonal Skills & Cyber Presence/Safety \\
\hline Relationships: Developing and Maintaining Healthy Relationships & $\begin{array}{l}\text { Validate Sources of Information } \\
\text { Maintain Safe Identity }\end{array}$ \\
\hline 4. Personal Improvement & 10. Residence \\
\hline Thinking Skills & Locating Housing Options \\
\hline $\begin{array}{l}\text { Personal Development; Learn About Talents, Interests, Skills, } \\
\text { Personality }\end{array}$ & Maintenance: A Basic Guide to Simple Home Maintenance \\
\hline $\begin{array}{l}\text { Personal Development; Explore Hobbies/Social/Recreational } \\
\text { Opportunities }\end{array}$ & Ownership: A Basic Guide to Buying Your Home \\
\hline Explore Tertiary Options (Tertiary education options) & $\begin{array}{l}\text { Renting: A Basic Guide to Renting Your Home } \\
\text { Upkeep: A Basic Guide to Upkeep of your Home } \\
\text { (Ex: Cleaning, Laundry) } \\
\text { Utilities: How to Set Up and Pay Utilities (Ex: Electricity, Water) }\end{array}$ \\
\hline 5. Finance & 11. Transportation \\
\hline Budgeting & Bicycling \\
\hline Open and Use a Savings Account & Driver's Responsibility: Following Laws \\
\hline Open, Use, and Balance a Checking Account & $\begin{array}{l}\text { Driver's Responsibility: Navigation, Reading a Map, and Using } \\
\text { GPS }\end{array}$ \\
\hline Building Credit/Credit Score & $\begin{array}{l}\text { Public Transportation: A Basic Guide to Using Public } \\
\text { Transportation }\end{array}$ \\
\hline Avoiding Debt & $\begin{array}{l}\text { Vehicle Maintenance: A Basic Guide to Simple Vehicle } \\
\text { Maintenance }\end{array}$ \\
\hline Investing & Vehicle Ownership: Buying a Vehicle \\
\hline Taxes & Vehicle Ownership: Leasing a Vehicle \\
\hline How to Use a Bank, an ATM, and Online Banking & $\begin{array}{l}\text { Vehicle Ownership: Purchasing Insurance } \\
\text { Vehicle Ownership: Title and Registration }\end{array}$ \\
\hline
\end{tabular}

6. Legal Documents

Keeping Track of Documents

Birth Certificate: Getting Your Birth Certificate

Driver's License: Getting Your Driver's License

Social Security Card: Getting Your Social Security Card

State Identification

Getting Your State ID

Table 4

Descriptive Statistics for Independent Living Dimensions

\begin{tabular}{llllll}
\hline Survivors & Mean & $S D$ & Non-survivors & Mean & $S D$ \\
\hline Interpersonal Improvement & 5.53 & 0.17 & Interpersonal improvement & 5.62 & 0.13 \\
Personal Improvement & 5.32 & 0.17 & Finance & 5.54 & 0.13 \\
Employment & 5.26 & 0.52 & Personal improvement & 5.52 & 0.14 \\
Safety/Security & 5.25 & 0.19 & Employment & 5.49 & 0.35 \\
Residence & 5.22 & 0.22 & Safety/Security & 5.47 & 0.16 \\
Health & 5.21 & 0.16 & Health & 5.45 & 0.10 \\
Legal Documents & 5.10 & 0.10 & Nutrition & 5.36 & 0.17 \\
Transportation & 5.05 & 0.46 & Civic duty & 5.33 & 0.16 \\
Civic Duty & 5.04 & 0.41 & Residence & 5.31 & 0.12 \\
Finance & 5.02 & 0.22 & Legal documents & 5.30 & 0.09 \\
Nutrition & 4.88 & 0.17 & Transportation & 5.17 & 0.40 \\
\hline
\end{tabular}


An analysis of variance with identification as an abuse survivor as the dependent variable showed that there was no main effect for any of the demographic variables, including gender $F(1,83)=0.604, p>0.05$, education level $F(4,83)=0.428, p>0.05$, marital status $F(2,83)=2.371, p>0.05$, employment status $F(4,83)$ $=0.613, p>0.05$, or household income $F(7,83)=0.222, p>0.05$. Thus, no particular demographic group was more likely to be identified as a survivor of childhood abuse.

\section{Discussion}

This study was designed to extend upon current research by examining what learning resources child abuse survivors desire to utilize. This study also examined the differences in desired learning resources between child abuse survivors and non-abused individuals. Before turning to a discussion of the present study, a number of limitations should be noted.

First, the participants of the present study were college students, and these participants were students from only one university. It is known that young adults who were abused as children are less likely to attend a university (Blome, 1997; Courtney et al., 2011; Dworsky et al., 2014), thus, obtaining participants from a non-university sample might have provided a larger number of participants who were identified as child abuse survivors. Additionally, examining participants from a broader geographic region might also result in different findings. Thus, future studies should survey a wider range of participants, in age, educational status, and geographic location.

A related limitation is the sample size of the current study. While there were 159 participants who completed the survey, 26, or roughly $16 \%$, of those participants were identified as survivors of childhood abuse. According to the U.S. Department of Health and Human Services (2013), 47.1 children per every 1,000 children were reported as abused in a single year, meaning that roughly $5 \%$ of children are likely to be reported as being abused at some point during their childhood. Thus, the prevalence rate of child abuse survivors reported in the present study was slightly above the national average of the prevalence rate of reported cases of suspected abuse each year. It has been stated that less than half to roughly two-thirds of child abuse survivors were reported that they had people to whom they could turn for resources and to help them with their problems (Courtney et al., 2011). Thus, it is possible that the rate of those who were identified as survivors of child abuse in the present study is higher than the overall average because much child abuse goes unreported, and the national average is an underestimate of the actual rate, and this study presented survivors with an opportunity to speak for themselves anonymously. Additionally, the present study has the potential to fall victim to the common limitations of self-report data. Despite the small sample of child abuse survivors, there were differences in what the survivors desired most, as compared to non-abused individuals. We believe that these are valuable insights, and future studies should examine these issues including a larger sample of abuse survivors.

Despite these limitations, there are a number of important contributions made by the present study. First, this study examined what types of resources would be useful for young adults who were abused as children. A large majority of research on childhood abuse has focused on the negative effects of the abuse, rather than how to help those young adults who have grown up as victims of maltreatment. This is an invaluable area of research, especially with regard to developing interventions to help these young adults to start their lives successfully. Because of the low rate of child abuse victims who have access to resources for overcoming their negative childhood experiences (Courtney et al., 2011), it is vital for organizations seeking to help these individuals to determine what types of interventions will be most useful and desirable. 
Furthermore, the present study identified a number of areas for which childhood abuse survivors would like to have learning resources, in order to help them become successful adults. For the specific questionnaire items, Interpersonal Skills, Finding a Job, Keeping a Job, Communication Skills, and Job Applications were identified as the top five areas in which child abuse survivors are interested. At the dimension level, child abuse survivors were most interested in obtaining resources regarding Interpersonal Improvement, Personal Improvement, Employment, Safety/Security, and Residence. With regard to the overall dimensions, the most striking difference between survivors and non-abused individuals was that non-abused individuals ranked Finance as their second-most desired area of resources, whereas for survivors, Finance was ranked tenth (out of eleven).

Consistent with previous research, it makes sense that child abuse survivors reported interest in learning about interpersonal skills, including communication skills, because they are likely to be at risk of failing to develop appropriate interpersonal skills, and they may not be willing to commit to romantic relationships (Alexandrov et al., 2005; Shields \& Cicchetti, 1998). Child abuse survivors may desire benefits provided by healthy relationships and therefore may be driven to develop them in order to acquire such benefits.

It is also not surprising that survivors are interested in finding and keeping a job as well as obtaining information on applying for jobs because survivors of childhood abuse report difficulty in locating and obtaining full-time work, and they reported that they desire full-time work (Courtney et al., 2011). Indeed, Courtney et al. (2011) also found that two-thirds of young women and $42 \%$ of young men were food stamp recipients, and abuse survivors in the present study reported that they desire to learn more about Safety/Security. Perhaps, learning how to obtain more stable income can provide a sense of Safety/Security in that survivors can sufficiently nourish themselves without worry. Child abuse survivors are likely to experience higher rates of unemployment and homelessness (Jackson \& Martin, 1998; Thornberry et al., 2001), and housing insecurity associated with maternal stress is directly related to abuse and neglect risk (Warren \& Font, 2015). Food scarcity and housing insecurity may be related to lack of income, so acquiring job related skills that increase work stability and income can potentially help child abuse survivors eliminate food scarcity and housing insecurity. Thus, eliminating food scarcity and housing insecurity can, in turn, increase survivors' sense of Safety/Security. According to Maslow (1943), people will most likely be motivated to achieve meeting lower-level needs, such as food, water, safety, security, relationships, and feelings of accomplishment before meeting their upper-level needs, such as self-actualization, which includes achieving one's full potential. Thus, if child abuse survivors can achieve these lower-level needs, they may be more likely to move towards achieving self-actualization and therefore be more likely to achieve their desired success as adults.

Additionally, child abuse survivors' third most desirable resource was Keeping a Job, whereas for non-abused individuals, Keeping a Job was ranked ninth. Child abuse survivors may be more concerned with Keeping a Job while non-abused individuals are more concerned with Work Ethic due to differences in parental job stability. Child abuse survivors may be more likely to come from low-income households in which their parents had unstable jobs or were unemployed, which may lead them to be more interested in learning how to keep a job. Non-abused individuals may have come from households of higher incomes in which parents had stable jobs, which may lead them to be more interested in work ethic. Finally, with regard to non-abused individuals' much greater interest in Finance, as compared with child abuse survivors, this may be because non-abused individuals may have grown up in a more financially stable environment and therefore may be more concerned with building and managing wealth. Oppositely, child abuse survivors may be more likely to 
come from lower-income homes and may be more concerned with developing skills that will help them meet their basic needs, such as learning how to write a resume to help themselves get a job so that they can provide themselves with food, shelter, and clothing, before they are concerned with accruing wealth. It is also possible that, due to being raised in lower-income homes, child abuse survivors may not have been introduced to the concept of wealth building and management, and therefore it may not be of interest to them because it may be a foreign subject.

While the differences in interests between individuals who were identified as survivors of childhood abuse and those who was not identified as such are quite interesting, from a broader point of view, the results of this study reveal that child abuse survivors desire utilizing certain learning resources more than others. Knowing what child abuse survivors are most interested in will aid in the development of interventions targeted at those areas of life in which survivors need the most help. If programs are aimed at topics that abuse survivors do not find valuable or important, those programs may likely not be well attended by child abuse survivors, and thus those programs may be less effective. Interventions that target child abuse survivors' most desired resources may likely be used by survivors, which will serve to maximize the number of survivors who can be helped by these programs.

The results of the present study point to a number of avenues for future research, in order to help influence the development interventions aimed at aiding adult survivors of child abuse. First, future research should examine these areas of life using larger, more diverse (in age, educational status, and geographic location) samples to help determine how generalizable the results are to the population of childhood abuse survivors. Second, future research should examine other areas of life, such as reproductive issues, to determine their relative importance to survivors of abuse. Importantly, this research serves as a starting point to shift more focus to how we can help people who were abused as children develop into successful, productive adults.

Additionally, the results of such research can be used for a number of real-world, practical applications. The results of this study and other similar studies using larger, more diverse samples can have a number of important uses for programs hoping to help adult survivors of childhood abuse. The data collected in the present study can be used to develop self-help resources for child abuse survivors. For example, websites and brochures targeting the most important areas to abuse survivors can be published and used by shelters and counselors.

This data can also be used by shelters that serve child abuse survivors in order to design and implement therapeutic programs for clients. For example, a shelter that implements a weekly art therapy program may incorporate a project that involves helping survivors establish self-worth through positive affirmation painting in order to reduce shame that can interfere with relationships. Shelters can also use the research to reprioritize programs in accordance with the desires of child abuse survivors, for example, making a weekly interpersonal skills group a priority. Furthermore, mental health professionals, such as counseling and clinical psychologists, can use these data to reprioritize how they serve their clients. For example, a therapist who is working with a survivor of child abuse may focus on helping his or her client recognize healthy patterns of relating or suggest personal development literature related to employment skills.

College campuses can use this information to provide resources for their students who are child abuse survivors in order to help them succeed in college. Departments such as University Housing can market these resources to incoming freshman and make them available to help their students succeed in their goals. Government agencies such as the Department of Human Services (DHS) can use this information to provide 
resources to their clients, including training in interpersonal skills and employment skills, as well as basic meal plans and basic budgeting advice.

Overall, this research can be used by those who are serving child abuse survivors by designing and implementing programs that are consistent with the priority of what is desired by child abuse survivors. Additionally, researchers can use the findings of this study as a launching point to focus research on helping child abuse survivors develop into successful adults. In addition to focusing on the negative effects of abuse, researchers can focus on healing survivors.

The purpose of this study is to do just that: create programs targeted at what child abuse survivors want most in order to help them with the resources that are most important to them. The results from this study will be used in the creation and implementation of programs aimed at helping child abuse survivors succeed in independent adult living, therefore providing them with support which they may currently be lacking, via the philanthropic movement, No Longer Silenced Movement. In the future, program evaluations may be conducted as necessary on each program, and programs may be revised accordingly to ensure that survivors of child abuse are receiving resources that are truly beneficial to their individual success.

In conclusion, much research prior to the present study focused on the detrimental effects of child abuse while less focus was given to what can be done to help adult child abuse survivors heal. The present study was conducted in order to expand upon the current research by examining what learning resources young adult survivors of child abuse may be interested in utilizing in order to help them succeed in adult living. This study found that child abuse survivors are most interested in resources related to Interpersonal Skills, Personal Improvement, and Employment Skills. Moving forward, this research can be used to design and implement programs to help survivors heal in accordance with what they want as well as to guide research toward focusing on survivor healing. While the complete prevention of child abuse may not be feasible, it is possible to improve, increase, and extend our outreach efforts to those affected by child abuse so that they can rebuild their lives and become successful, self-sufficient adults, and productive members of society.

\section{References}

Alexandrov, E. O., Cowan, P. A., \& Cowan, C. P. (2005). Couple attachment and the quality of marital relationships: Method and concept in the validation of the new couple attachment interview and coding system. Attachment \& Human Development, $7(2), 123-152$.

Alpher, V. S., \& France, A. C. (1993). Interpersonal complementarity and appeasement in relationships with initiators of childhood psychosocial trauma. Psychotherapy: Theory, Research, Practice, Training, 30(3), 502.

Artime, T. M., \& Peterson, Z. D. (2012). The relationships among childhood maltreatment, emotion regulation, and sexual risk taking in men from urban STD clinics. Journal of Aggression, Maltreatment \& Trauma, 21(3), 277-299.

Burns, E. E., Jackson, J. L., \& Harding, H. G. (2010). Child maltreatment, emotion regulation, and posttraumatic stress: The impact of emotional abuse. Journal of Aggression, Maltreatment \& Trauma, 19(8), 801-819.

Banyard, V. L., \& Williams, L. M. (2007). Women's voices on recovery: A multi-method study of the complexity of recovery from child sexual abuse. Child Abuse \& Neglect, 31(3), 275-290.

Blome, W. W. (1997). What happens to foster kids: Educational experiences of a random sample of foster care youth and a matched group of non-foster care youth. Child and Adolescent Social Work Journal, 14(1), 41-53.

Child Welfare Information Gateway. (2015). Understanding the effects of maltreatment on brain development. Washington, DC: U.S. Department of Health and Human Services, Children's Bureau.

Cicchetti, D., \& White, J. (1990). Emotion and developmental psychopathology. Psychological and Biological Approaches to Emotion, 359-382.

Collin-Vézina, D., Isabelle, D., \& Martine, H. (2013). Lessons learned from child sexual abuse research: Prevalence, outcomes, and preventive strategies. Child and Adolescent Psychiatry and Mental Health, 7(1), 22. 
Courtney, M., Dworsky, A., Brown, A., Cary, C., Love, K., \& Vorhies, V. (2011). Midwest evaluation of the adult functioning of former foster youth: Outcomes at age 26. Chicago, IL: Chapin Hall at the University of Chicago.

DiLillo, D., Lewis, T., \& Di Loreto-Colgan, A. (2007). Child maltreatment history and subsequent romantic relationships: Exploring a psychological route to dyadic difficulties. Journal of Aggression, Maltreatment \& Trauma, 15(1), 19.

Dube, S. R., Anda, R. F., Felitti, V. J., Chapman, D. P., Williamson, D. F., \& Giles, W. H. (2001). Childhood abuse, household dysfunction, and the risk of attempted suicide throughout the life span: Findings from the adverse childhood experiences study. JAMA, 286(24), 3089-3096.

Dworsky, A., Smithgall, C., \& Courtney, M. E. (2014). Supporting youth transitioning out of foster care. Washington, DC: Office of Planning, Research and Evaluation, Administration for Children and Families, U.S. Department of Health and Human Services.

Fang, X., Brown, D. S., Florence, C. S., \& Mercy, J. A. (2012). The economic burden of child maltreatment in the United States and implications for prevention. Child Abuse \& Neglect, 36(2), 156-165.

Feiring, C. (2005). Emotional development, shame, and adaptation to child maltreatment. Child Maltreatment, 10(4), $307-310$.

Ginsberg, L. H., Nackerud, L. G., \& Larrison, C. R. (2004). Human biology for social workers: Development, ecology, genetics, and health. Boston: Pearson/Allyn and Bacon.

Greenfeld, L. A., \& Snell, T. L. (1999). Women offenders. Washington, DC: US Department of Justice, Office of Justice Programs, Bureau of Justice Statistics.

Herrenkohl, T. I., Seunghye, H., Klika, J. B., Herrenkohl, R. C., \& Russo, M. J. (2013). Developmental impacts of child abuse and neglect related to adult mental health, substance use, and physical health. Journal of Family Violence, 28(2), 191-199.

Jackson, S., \& Martin, P. Y. (1998). Surviving the care system: Education and resilience. Journal of Adolescence, 21(5), $569-583$.

Jackowski, A. P., De Araújo, C. M., De Lacerda, A. L. T., De Jesus Mari, J., \& Kaufman, J. (2009). Neurostructural imaging findings in children with post-traumatic stress disorder: Brief review. Psychiatry and Clinical Neurosciences, 63(1), 1-8.

Kandel, E. R., Schwartz, J. H. I., \& Jessell, T. M. (2000). Principles of neural science (4th ed.). New York: McGraw-Hill, Health Professions Division.

Kim, J., Talbot, N. L., \& Cicchetti, D. (2009). Childhood abuse and current interpersonal conflict: The role of shame. Child Abuse \& Neglect, 33(6), 362-371.

Kimbrough, E., Magyari, T., Langenberg, P., Chesney, M., \& Berman, B. (2010). Mindfulness intervention for child abuse survivors. Journal of Clinical Psychology, 66(1), 17-33.

Krystal, J. H., Kosten, T. R., Southwick, S., Mason, J. W., Perry, B. D., \& Giller, E. L. (1989). Neurobiological aspects of PTSD: Review of clinical and preclinical studies. Behavior Therapy, 20(2), 177-198.

Loader, P. (1998). Such a shame-A consideration of shame and shaming mechanisms in families. Child Abuse Review, 7(1), 44-57.

Lynch, S. M., Fritch, A., \& Heath, N. M. (2012). Looking beneath the surface: The nature of incarcerated women's experiences of interpersonal violence, treatment needs, and mental health. Feminist Criminology, 7(4), 381-400.

Maslow, A. H. (1943). A theory of human motivation. Psychological Review, 50(4), 430-437.

Miller-Perrin, C. L., Wurtele, S. K., \& Kondrick, P. A. (1990). Sexually abused and nonabused children's conceptions of personal body safety. Child Abuse \& Neglect, 14(1), 99-112.

Nakou, S., Adam, H., Stathacopoulou, N., \& Agathonos, H. (1982). Health status of abused and neglected children and their siblings. Child Abuse \& Neglect, 6(3), 279-284.

Painter, K., \& Scannapieco, M. (2013). Child maltreatment: The neurobiological aspects of posttraumatic stress disorder. Journal of Evidence-based Social Work, 10(4), 276-284.

Perry, B. D. (1994). Neurobiological sequelae of childhood trauma: Post-traumatic stress disorders in children. In M. Murburg (Ed.), Catecholamine function in post-traumatic stress disorder: Emerging concepts (pp. 253-276). Washington, DC: American Psychiatric Press.

Perry, B. D., Pollard, R., Blakely, T., Baker, W., \& Vigilante, D. (1995). Childhood trauma, the neurobiology of adaptation, and "use-dependent" development of the brain: How "states" become "traits". Infant Mental Health Journal, 16(4), 271-291.

Ross, T. (2010). Where the money comes from: Paying for child welfare services. Retrieved from http://www.childwelfarepolicy.org/perspectives?id=0001

Scannapieco, M., \& Connell-Carrick, K. (2005). Understanding child maltreatment: An ecological and developmental perspective. New York: Oxford University Press.

Schelble, J. L., Franks, B. A., \& Miller, M. D. (2010). Emotion dysregulation and academic resilience in maltreated children. Child \& Youth Care Forum, 39(4), 289-303. 
Schraedley, P. K., Turner, R. J., \& Gotlib, I. H. (2002). Stability of retrospective reports in depression: Traumatic events, past depressive episodes, and parental psychopathology. Journal of Health \& Social Behavior, 43(3), 307-316.

Senn, T. E., Carey, M. P., Vanable, P. A., Coury-Doniger, P., \& Urban, M. A. (2006). Childhood sexual abuse and sexual risk behavior among men and women attending a sexually transmitted disease clinic. Journal of Consulting and Clinical Psychology, 74(4), 720.

Shields, A., \& Cicchetti, D. (1998). Reactive aggression among maltreated children: The contributions of attention and emotion dysregulation. Journal of Clinical Child Psychology, 27(4), 381-395.

Silverman, A. B., Reinherz, H. Z., \& Giaconia, R. M. (1996). The long-term sequelae of child and adolescent abuse: A longitudinal community study. Child Abuse \& Neglect, 20(8), 709-723.

Solomon, E. P., \& Heide, K. M. (2005). The biology of trauma: Implications for treatment. Journal of Interpersonal Violence, 20(1), 51-60.

Tang, B., Jamieson, E., Boyle, M., Libby, A., Gafni, A., \& MacMillan, H. (2006). The influence of child abuse on the pattern of expenditures in women's adult health service utilization in Ontario, Canada. Social Science \& Medicine, 63(7), 1711-1719.

Terr, L. C. (1983). Chowchilla revisited: The effects of psychic trauma four years after a school-bus kidnapping. American Journal of Psychiatry, 140(12), 1543-1550.

Terr, L. C. (1991). Childhood traumas: An outline and overview. American Journal of Psychiatry, 148(1), 10-20.

Thompson, M. P., Arias, I., Basile, K. C., \& Desai, S. (2002). The association between childhood physical and sexual victimization and health problems in adulthood in a nationally representative sample of women. Journal of Interpersonal Violence, 17(10), 1115-1129.

Thornberry, T. P., Ireland, T. O., \& Smith, C. A. (2001). The importance of timing: The varying impact of childhood and adolescent maltreatment on multiple problem outcomes. Development and Psychopathology, 13(04), 957-979.

US Department of Health and Human Services. (2001). National survey of child and adolescent well-being (NSCAW): One year in foster care report.

US Department of Health and Human Services. (2013). Child maltreatment.

Van der Kolk, B. A. (1987). The separation cry and the trauma response: Developmental issues in the psychobiology of attachment and separation. Psychological Trauma, 31-61.

Wang, C. T., \& Holton, J. (2007). Total estimated cost of child abuse and neglect in the United States. Chicago, IL: Prevent Child Abuse America.

Walker, E. A., Unutzer, J., Rutter, C., Gelfand, A., Saunders, K., VonKorff, M., ... \& Katon, W. (1999). Costs of health care used by women HMO members with a history of childhood abuse and neglect. Archives of General Psychiatry, 56(7), 609-613.

Warren, E. J., \& Font, S. A. (2015). Housing insecurity, maternal stress, and child maltreatment: An application of the family stress model. Social Service Review, 89(1), 9-39. 